\title{
Uso de fertilizante organomineral no desenvolvimento de mudas de rúcula
}

\author{
Roberta Camargos Oliveira ${ }^{1 *}$, João Eduardo Ribeiro Silva ${ }^{1}$, Ariel Santivañez Aguilar ${ }^{1}$, Diego Peres ${ }^{1}$, Jose \\ Magno Queiroz Luz ${ }^{1}$
}

\begin{abstract}
RESUMO: A rúcula é uma brássica cujas folhas são ricas em vitaminas, sais minerais e apresentam efeito medicinal. A produção de mudas é uma etapa importante do sistema de produção de hortaliças, pois influencia o desenvolvimento, o ciclo, a qualidade e a quantidade a ser produzida. Dentre as práticas de manejo, o uso de produtos organominerais líquidos ainda é recente. Diante disso, objetivou-se avaliar o efeito do carbono orgânico proveniente de um fertilizante organomineral líquido no desenvolvimento inicial de mudas de rúcula. $\mathrm{O}$ experimento, em delineamento de blocos ao acaso, em esquema fatorial $(4 \times 2)+1$, avaliou-se quatro doses $(0,50 ; 0,75 ; 1,00$ e $1,25 \%)$, duas fontes (Sulfato de zinco e fertilizante organomineral líquido) mais um tratamento testemunha sem a aplicação de produtos. A coleta das plantas foi realizada 32 dias após a semeadura. A presença de carbono orgânico é favorável ao desenvolvimento de mudas de rúcula. A aplicação do fertilizante organomineral líquido resultou em melhores médias das variáveis comprimento de raiz, número de folhas, massa seca da parte aérea, massa seca raiz, teor de clorofila $\mathrm{A}$ e teor de clorofila total em comparação com o sulfato de zinco, porém sem efeito em relação à testemunha.
\end{abstract}

Palavras-chave: Eruca sativa, clorofila, adubação líquida, hortaliça

\section{Use of fertilizer organomineral in rocket seedlings development}

\begin{abstract}
The rocket is a brassica with leaves are rich in vitamins, minerals and have medicinal effect. The seedling production is an important step of the vegetable production system, because it influences the development cycle, the quality and quantity to be produced. Among the management practices, the use of liquid biofertilizers is still new. The research objective was to evaluate the effect of organic carbon from an organomineral liquid fertilizer in the early development of rocket seedlings. The experiment, in randomized block design, in factorial $(4 \times 2)+1$, evaluated four doses $(0.50,0.75,1.00$ and $1.25 \%)$, two sources (zinc sulphate organomineral fertilizer liquid) over witness, without the application of products. The collection of plants was carried out 32 days after sowing. The presence of organic carbon supports the development of rocket seedlings. Application of organic-liquid fertilizer resulted in better average of root length variables, number of leaves, dry weight of shoot, dry root mass, chlorophyll A content and total chlorophyll content compared with zinc sulfate, but without effect compared to witness.
\end{abstract}

Keywords: Eruca sativa, chlorophyll, liquid fertilizer, vegetable

\section{INTRODUÇÃO}

A rúcula (Eruca sativa L.) é uma brássica cujas folhas são muito apreciadas na forma de salada. No Brasil, sua produção e consumo são destacados nas regiões Sul, Sudeste e Nordeste, gerando emprego e renda à agricultura familiar (SILVA et al., 2012a). Por apresentar sistema simples de plantio, rápido crescimento vegetativo e ciclo curto, vem conquistando cada vez mais espaço no mercado (COSTA et al., 2011).

$\mathrm{Na}$ Companhia de Entrepostos e Armazéns Gerais do Estado de São Paulo (CEAGESP), o maior centro de abastecimento de frutas e verduras do país, entre 1997 e 2003 a quantidade de rúcula comercializada teve um crescimento de $78 \%$. No final de 2014 e início de 2015 , o preço da rúcula permaneceu na faixa de $\mathrm{R} \$ 3,13 \mathrm{~kg}^{-1}$ (CEAGESP,
2015), o que caracteriza esta cultura como de elevado valor de comercialização, comparado a outras folhosas.

No contexto atual de produção de hortaliças, a produção de mudas de qualidade, por ser uma das primeiras etapas do processo produtivo, assume importância fundamental em função do seu efeito no desempenho final das plantas no campo de produção (CERQUEIRA et al., 2015). A produção em larga escala de mudas de boa qualidade tem motivado os produtores a adotarem técnicas mais modernas, procurando obter mudas de melhor qualidade.

A alta qualidade da muda é essencial, uma vez que a condição inicial da planta afeta o pegamento das mudas no campo, a produção precoce e a produção total (SILVA et al., 2012b). Apesar do 
conhecimento da necessidade de obtenção de mudas de boa procedência e qualidade, existe ainda carência de informações e de técnicas que permitam melhores resultados na etapa de produção de mudas, principalmente em relação ao seu manejo nutricional e fitossanitário.

Uma das linhas de estudo voltadas para a nutrição de hortaliças considera o uso de compostos orgânicos como fontes de nutrientes para esse tipo de cultura. Dentre os materiais estudados estão os fertilizantes organominerais, os quais se caracterizam pela mistura de uma fonte de matéria orgânica a um fertilizante mineral. A utilização da adubação organomineral é considerada uma das alternativas para propiciar maior rendimento das culturas e melhor qualidade da produção (ANDRADE et al., 2012).

$O$ principal motivo na adição de nutrientes minerais aos fertilizantes orgânicos é diminuir a taxa de mineralização, fixação e lixiviação dos nutrientes. Além disso, esses fertilizantes orgânicos têm o inconveniente de não apresentar proporções fixas e definidas de NPK, ao contrário das fórmulas comerciais de fertilizantes minerais, onde sua composição pode ser balanceada de acordo com a planta e o solo (SOUSA et al., 2012).

A forma líquida de fertilizantes organominerais enquadra-se nas categorias de ativantes biológicos, estimulantes e reguladores de crescimento, fontes de nutrientes minerais de baixa concentração, condicionadores e agentes umectantes. Esse tipo de produto é relativamente novo e ainda pouco estudado, do mesmo modo que a sua utilização em culturas olerícolas. Assim, não existem, ainda, vastas informações sobre o modo de ação desses produtos e seu efeito em hortaliças.

Diante desse contexto, objetivou-se avaliar o efeito do carbono orgânico proveniente de um fertilizante organomineral líquido no desenvolvimento inicial de mudas de rúcula.

\section{MATERIAL E MÉTODOS}

O experimento foi instalado em março de 2014, em casa de vegetação, com cobertura de vidro. Foram utilizadas sementes de rúcula, bandejas de isopor de 200 células e substrato para formação de mudas marca Carolina Padrão.

O delineamento experimental utilizado foi o de blocos casualizados, com quatro repetições. Os tratamentos foram distribuídos em esquema fatorial $(4 \times 2)+1$, sendo quatro doses de fertilizante líquido $(0,50 ; \quad 0,75 ; 1,00$ e $1,25 \%)$, duas fontes (organomineral Sulfato de Zinco) e um tratamento testemunha sem a aplicação adicional de fertilizantes (Tabela 1).

As doses testadas foram calculadas com base na dose comercial indicada pelo fabricante do fertilizante organomineral líquido $(1,00 \% \mathrm{v} / \mathrm{v})$. Tal dose é recomendada para a aplicação em mudas via água de irrigação, considerando que o produto pode ser absorvido tanto via foliar, como radicular. Assim utilizaram-se duas doses de menor concentração e uma de maior concentração (Tabela 1).

Tabela 1. Tipo de fertilizante e dose aplicada em cada um dos tratamentos

\begin{tabular}{ccc}
\hline Tratamento & Fonte & Dose \\
\hline 1 & Organomineral líquido & $0,50 \%$ \\
2 & Organomineral líquido & $0,75 \%$ \\
3 & Organomineral líquido & $1,00 \%$ \\
4 & Organomineral líquido & $1,25 \%$ \\
5 & Sulfato de Zinco & $0,50 \%$ \\
6 & Sulfato de Zinco & $0,75 \%$ \\
7 & Sulfato de Zinco & $1,00 \%$ \\
8 & Sulfato de Zinco & $1,25 \%$ \\
\hline
\end{tabular}

$\mathrm{O}$ organomineral avaliado apresenta em sua composição carbono orgânico total e sulfato de zinco $\left(\mathrm{ZnSO}_{4}\right)$. A fonte $\mathrm{ZnSO}_{4}$ forneceu enxofre e zinco em quantidades equivalentes aos tratamentos à base do fertilizante organomineral, variando assim somente o carbono orgânico aplicado.

A descrição dos fertilizantes utilizados pode ser resumida a partir das seguintes informações:
Sulfato de Zinco $\left(\mathrm{ZnSO}_{4}\right): 20 \% \mathrm{Zn} ; 9,11 \%$ S; Fertilizante organomineral líquido: $59,5 \mathrm{~g} \mathrm{~L}^{-1}$ $\mathrm{Zn} ; 29,75 \mathrm{~g} \mathrm{~L}^{-1} \mathrm{~S} ; 54,74 \mathrm{~g} \mathrm{~L}^{-1}$ carbono orgânico total.

Considerando essas informações e fazendo as equivalências, as quantidades aplicadas em cada um dos tratamentos seguiram as proporções apresentadas na tabela a seguir (Tabela 2). 
Tabela 2. Relação das quantidades de nutrientes aplicados para cada fertilizante

\begin{tabular}{lllcl}
\hline \multirow{2}{*}{ Tratamentos } & \multicolumn{4}{c}{ Concentração (\%) } \\
\cline { 2 - 5 } & 0,5 & 0,75 & 1,00 & 0,25 \\
\hline Formulado $(\mathrm{mL})$ & 0,16 & 0,24 & 0,32 & 0,40 \\
Zn $(\mathrm{g})$ & 0,03 & 0,05 & 0,07 & 0,09 \\
\hline
\end{tabular}

As parcelas experimentais foram compostas por 20 células da bandeja, sendo a bordadura formada por duas fileiras, totalizando também 20 células.

A aplicação foi realizada aos 18 e 25 dias após a emergência das plantas, quando estas apresentavam de duas a quatro folhas abertas.

As doses de cada produto utilizadas nos tratamentos foram diluídas em $160 \mathrm{~mL}$ de água destilada e, com o auxílio de uma seringa com capacidade de 10,0 mL, aplicou-se 2,0 mL da solução em cada uma das 20 células de cada repetição.

Para isolar o efeito da água utilizada unicamente como veículo na aplicação, o tratamento testemunha recebeu aplicação somente de água destilada, na mesma quantidade dos demais tratamentos.

A coleta das plantas para avaliação foi realizada 32 dias após a semeadura, retirando-se 10 plantas por parcela, procedendo-se a lavagem das raízes em água corrente para remoção do substrato a elas aderido.

Antes da coleta das plantas, avaliou-se o teor das clorofilas A e B nas folhas, utilizando-se um clorofilômetro (marca Falker, modelo Clorofilog CFL 1030) com dispositivo de formação de câmara a qual analisa parte da folha da planta, sem que a mesma seja destacada. A partir desse resultado, pela soma dos teores das clorofilas A e B estimou-se o teor de clorofila total.

Foram avaliados também o comprimento e o peso seco de parte aérea e de raízes, o diâmetro do caule e o número de folhas.

As medições de comprimento de parte aérea e raiz foram feitas com o auxílio de régua milimetrada e o diâmetro do caule foi medido utilizando-se paquímetro digital.

Para a obtenção dos pesos secos, as plantas foram acondicionadas em sacos de papel e secas em estufa à $65^{\circ} \mathrm{C}$ por 72 horas. A pesagem das plantas, separadas em raiz e parte aérea, foi realizada em balança digital, com precisão de quatro casas decimais.

Os dados foram submetidos à análise de variância e, em caso de significância dos valores de F, foram comparados com a testemunha pelo teste de Dunnett e, entre si, pelo teste de Tukey, ambos a 0,05 de significância, com o auxílio do programa estatístico Assistat, e por regressões com o auxílio do programa Sisvar.

As pressuposições de normalidade dos resíduos, homogeneidade das variâncias e aditividade de blocos foram testadas pelo programa estatístico SPSS, todos a 0,05 de significância.

\section{RESULTADOS E DISCUSSÃO}

O comprimento de raiz, número de folhas, massa seca de parte aérea, massa seca de raiz, clorofila A e clorofila total variaram em função do fertilizante utilizado, sendo o fertilizante organomineral líquido superior ao sulfato de zinco em todas essas variáveis (Tabela 3 ).

Tabela 3. Comprimento de raiz (CR), número de folhas (NF), massa seca de parte aérea (MSPA), massa seca de raiz (MSR), clorofila A (ClorA) e clorofila total (ClorTot) de mudas de couve rúcula submetidas a adubação com diferentes fertilizantes. Médias de quatro doses $(0,5 ; 0,75 ; 1,0$ e $1,25 \%)$

\begin{tabular}{|c|c|c|c|c|c|c|}
\hline Tratamento & $\mathrm{CR}$ & $\mathrm{NF}$ & MSPA & MSR & ClorA & ClorTot \\
\hline $\begin{array}{l}\text { Fert. OM Líquido } \\
\mathrm{ZnSO}_{4}\end{array}$ & $\begin{array}{l}--\mathrm{cm}-- \\
6,87 \mathrm{a}^{1} \\
6,08 \mathrm{~b}^{1}\end{array}$ & $\begin{array}{l}3,13 \mathrm{a}^{1} \\
2,67 \mathrm{~b}^{1}\end{array}$ & $\begin{array}{l}--g \text {-- } \\
0,42 a^{1} \\
0,31 b^{1}\end{array}$ & $\begin{array}{l}--g-- \\
0,08 a^{1} \\
0,06 b^{1}\end{array}$ & $\begin{array}{l}----1 \mu \\
26,87 \mathrm{a} \\
24,30 \mathrm{~b}\end{array}$ & $\begin{array}{l}32,19 a^{1} \\
29,25 b^{1}\end{array}$ \\
\hline DMS & 0,76 & 0,32 & 0,09 & 0,01 & 1,56 & 2,00 \\
\hline $\mathrm{CV}(\%)$ & 16,15 & 15,38 & 35,21 & 29,23 & 8,36 & 8,92 \\
\hline
\end{tabular}

Médias seguidas por letras distintas na coluna diferem entre si pelo teste de Tukey a 0,05 de significância. Médias seguidas por ${ }^{1}$ não diferem da testemunha pelo teste de Dunnett a 0,05 de significância

$\mathrm{O}$ efeito positivo do fertilizante organomineral está diretamente ligado à sua composição, pois estes produtos possuem em suas formulações componentes fúlvicos $\mathrm{e}$ húmicos presentes nas frações orgânicos que têm em geral a função de otimizar a absorção

dos nutrientes contidos nos mesmos. Entre os aspectos relevantes das frações húmica da matéria orgânica, pode-se citar: estimulante da flora microbiana em volta do sistema radicular, facilitador da retenção e liberação dos nutrientes, retenção de água, aeração, agregação 
do solo e a formação de quelatos naturais, o que influencia positivamente a nutrição da planta (SOUZA; RESENDE, 2003).

Vale ressaltar ainda que a matéria orgânica somada aos nutrientes minerais facilita a absorção destes últimos e auxilia no transporte de fotoassimilados elaborados pela própria planta (KIEHL, 1985). Isso pode resultar em plantas mais vigorosas e capazes de suportar melhor o estresse provocado pelo transplantio.

Benício et al. (2011) obtiveram resultados positivos da utilização de biofertilizante orgânico aplicado via foliar em mudas de couve, expressos pelo maior crescimento de mudas e maior produção de biomassa fresca proporcionadas pela aplicação do biofertilizante na concentração de $6 \%$, e pela maior biomassa seca resultante do uso do biofertilizante na concentração de $2 \%$.

Envolvendo também outras variáveis, em trabalho com adubação orgânica e mineral com diferentes arranjos espaciais entre as culturas da alface e rúcula em cultivo consorciado e solteiro, Oliveira et al. (2010) observaram maiores rendimentos de folhas da alface para o cultivo orgânico. Os mesmos autores notaram, também no cultivo orgânico, maior altura média e maior quantidade de massa seca da parte aérea de mudas de rúcula.

Outra possível explicação para o melhor desempenho do carbono orgânico em detrimento do micronutriente zinco é o seu efeito como condicionador de solo que proporciona melhor desenvolvimento radicular e consequentemente melhor absorção de nutrientes. Também, o efeito condicionante atuando na redução da lixiviação de nutrientes mesmo com regas diárias certamente favoreceu o desenvolvimento das mudas de rúcula, o que se confirmou pelo resultado das variáveis mencionadas.

Apesar das diferenças entre os produtos, para essas variáveis não se observou efeito da Tabela 4. Massa seca de raiz e teor de clorofila A de mudas de rúcula submetida à aplicação de diferentes doses de fertilizante organomineral líquido ou Sulfato de zinco.

\begin{tabular}{lll}
\hline Dose (\%) & Massa seca de raiz & Teor de Clorofila A \\
\hline & $----\mathrm{g}^{----}$ & $---\mathrm{g} \mathrm{mL}^{-1}---\mathrm{ab}^{1}$ \\
0,50 & $0,08 \mathrm{a}^{1}$ & $25,87 \mathrm{ab}^{1}$ \\
0,75 & $0,05 \mathrm{a}^{1}$ & $27,49 \mathrm{a}^{1}$ \\
1,00 & $0,08 \mathrm{a}^{1}$ & $23,94 \mathrm{~b}^{1}$ \\
1,25 & $0,07 \mathrm{a}^{1}$ & $25,06 \mathrm{ab}^{1}$ \\
\hline DMS & 0,03 & 2,95 \\
$\mathrm{CV}(\%)$ & 29,23 & 8,36 \\
\hline Médias seguidas por letras iguais na coluna não diferem entre si pelo teste de Tukey a 0,05 de significância. Médias seguidas por
\end{tabular}

aplicação dos mesmos em relação à testemunha sem adubação (Tabela 3). Esse resultado difere, por exemplo, dos encontrados por Luz et al. (2010) que constataram que, para produção comercial de mudas de alface cultivar "Vera", as plantas tratadas com os fertilizantes organominerais líquidos tiveram maior diâmetro, maior massa fresca de parte aérea e de raiz, quando comparado com a testemunha.

A falta de resposta dos tratamentos em relação à testemunha talvez possa ser explicada pelas boas condições de cultivo oferecidas também nesse tratamento. Possivelmente o substrato utilizado tenha sido capaz de oferecer as condições adequadas para o desenvolvimento inicial da planta, mesmo sem suplementação nutricional. Aliado a isso está o fato de que as avaliações foram feitas num período de tempo relativamente curto após a emergência das plântulas, o qual pode ter sido insuficiente para que as diferenças fossem detectadas. Segundo Freitas et al. (2013), substratos de boa qualidade caracterizam-se por apresentar capacidade em fornecer água, oxigênio e nutrientes às plantas, o que permite ambientes estáveis ao desenvolvimento das plantas.

Não houve ajuste de regressão significativo para massa seca de raiz e teor de clorofila $\mathrm{A}$, o que resultou na comparação dos resultados por meio de teste de médias (Tukey a 0,05 de significância). Observou-se que, apesar do F significativo, as doses dos fertilizantes não influenciaram a produção de massa seca de raiz, a qual variou de 0,056 a $0,083 \mathrm{~g}$ (Tabela 4). Por outro lado, notou-se que a aplicação de $0,75 \%$ foi superior à de $1 \%$, em relação ao teor de clorofila A, havendo entre esses tratamentos, um incremento de $14,8 \%$ no teor de clorofila (Tabela 4). As demais doses apresentaram resultados intermediários, não diferindo dos extremos citados acima (Tabela 4). 
A ausência de resposta quanto a dose para a variável massa seca de raiz se assemelha aos resultados de Sousa et al. (2009), que não observaram aumento significativo no peso das raízes de pimentão (Capsicum annuum L.) tratadas com diferentes doses de biofertilizante.

Porém, Medeiros et al. (2011), utilizando biofertilizante à base de esterco bovino e melaço de cana, observaram aumento na biomassa radicular em mudas de tomate cereja (Licopersicon pimpinelli folium), o que pode ser um indicador de que o efeito do biofertilizante sobre o sistema radicular varia de acordo com a espécie utilizada e os componentes totais dos produtos (BENÍCIO et al., 2011).

Benício et al. (2011) também obtiveram resposta positiva para o peso seco de raiz quando utilizaram concentração de $2 \%$ de biofertilizante orgânico aplicado via foliar em mudas de couve. Apesar desse resultado, na análise de variância, o peso seco de raiz não apresentou ajuste significativo em nenhum dos modelos testados, o que se assemelha ao resultado aqui apresentado.

Novamente, nenhuma dessas variáveis diferiu em relação à testemunha sem aplicação de nutrientes, independente da dose aplicada (Tabela 3). Esse fato talvez possa ser explicado pela proximidade entre as doses e das doses com a quantidade de nutrientes contidas no substrato (testemunha). Outro estudo feito com maior intervalo entre doses e/ou maiores doses poderia sanar essa dúvida e gerar condições de se estudar o efeito das quantidades aplicadas de cada fertilizante.

\section{CONCLUSÕES}

A presença de carbono orgânico é favorável ao desenvolvimento de mudas de rúcula.

A aplicação do fertilizante organomineral líquido proporciona aumento em comprimento de raiz, número de folhas, massa seca da parte aérea, massa seca raiz, teor de clorofila $\mathrm{A}$ e teor de clorofila total de mudas de rúcula, em comparação com o sulfato de zinco, porém sem efeito em relação à testemunha.

\section{AGRADECIMENTOS}

FAPEMIG e CAPES pelo auxílio financeiro.

\section{REFERÊNCIAS}

ANDRADE, E. M. G.; SILVA, H. S.; SILVA, N. S.; SOUSA JÚNIOR, J. R.; FURTADO, G. F. Adubação organomineral em hortaliças folhosas, frutos e raízes. Revista Verde, Pombal, v.7, n.3, p.7-11, 2012.

BENÍCIO, L. P. F.; SILVA, L. L.; LIMA, S. D. O. Produção de mudas de couve sob efeito de diferentes concentrações de biofertilizante. Revista Acta Tecnológica - Revista Científica, Maranhão, v.6, n.2, p.1-6, 2011.

CEAGESP. Disponível em: <http://www.ceagesp.gov.br/cotacoes/>. Acesso em: Jan., 2015.

CERQUEIRA, F. B.; FREITAS, G. A.; MACIEL, C. J.; CARNEIRO, J. S. S.; LEITE, R. C. Seedlings of tomato cv. Santa Cruz on different substrates. Journal of Bioenergy Food Science, Amapá, v.2, n.2, p.39-45, 2015. doi: 10.1590/S0100-69162012000500002

COSTA, C. M. F. DA.; JÚNIOR, S. S.; ARRUDA, G. D. DE.; SOUZA, S. B. S. de. Desempenho de cultivares de rúcula sob telas de sombreamento e campo aberto. Revista Semina: Ciências Agrárias, Londrina, v.32, n.1, p.93-102, 2011. doi: 10.5433/1679-0359.2011v32n1p93

FREITAS, G. A.; SILVA, R. R.; BARROS, H. B.; MELO, A. V.; ABRAHÃO, W. A. P. Produção de mudas de alface em função de diferentes combinações de substratos. Revista Ciência Agronômica, Fortaleza, v.44, n.1, p.159-166, 2013.

KIEHL, E. J. Fertilizantes Orgânicos. São Paulo: Editora Ceres, 1985. 492 p.

LUZ, J. M. Q.; OLIVEIRA, G.; QUEIROZ, A. A.; CARREON, R. Aplicação foliar de fertilizantes organominerais em cultura de alface. Horticultura Brasileira, Brasília, v.28, n.1, p.373-377, 2010.

MEDEIROS, R. F.; CAVALCANTE, L. F.; MESQUITA, F. O.; RODRIGUES, R. M.; SOUSA, G. G.; DINIZ, A. A. Crescimento inicial do tomateiro-cereja sob irrigação com águas salinas em solo com biofertilizantes bovino. Revista Brasileira de Engenharia Agrícola e Ambiental, Campina Grande, v.15, n.5, p.505-511, 2011. doi: 10.1590/S1415-43662011000500011

OLIVEIRA, E. Q.; SOUZA, R. J.; CRUZ, M. C. M.; MARQUES, V. B.; FRANÇA, A. C. Produtividade de alface e rúcula, em sistema consorciado, sob adubação orgânica e mineral. Horticultura Brasileira, Brasília, v.28, n.1, p.36-40, 2010

SILVA, A. O.; SOARES, T. M.; SILVA, E. F.; SANTOS, A. N.; KLAR, A. E. Consumo hídrico da rúcula em cultivo hidropônico NFT utilizando rejeitos de dessalinizador em Ibimirim - PE. Irriga, Botucatu, v.17, n.1, p.114-125, 2012a. 10.15809/irriga.2012v17n1p114 
SILVA, R. R.; RODRIGUES, L. U.; FREITAS, G. A.; MELO, A. V.; NASCIMENTO, I. R.; D’ANDRÉA, A. F. Influência de casca de arroz carbonizada em diferentes substratos na qualidade de mudas de tomateiro. Revista Brasileira de Ciências Agrárias, Recife, v.7, supl, p.803-809, 2012b. doi: 10.5039/agraria.v7isa2227

SOUZA, J. L; RESENDE, P. Manual de horticultura orgânica. Viçosa: Aprenda fácil. 2003. 564 p.

SOUSA, M. J. R.; MELO, D. R. M.; FERNANDES, D.; SANTOS, J. G. R.; ANDRADE, R. Crescimento e produção do pimentão sob diferentes concentrações de biofertilizante e intervalos de aplicação. Revista Verde, Pombal, v.4, n.4, p.42-48, 2009.
SOUSA, R. T. X.; HENRIQUE, H. M.; KORNDÖRFER, G. H. Teste de performance em híbridos de Milho com uso de Geofert em Santana de Vargem - MG. Empresa Geociclo, Minas Gerais. 10p, 2012. Disponível em: <http://www.geociclo.com.br/wpcontent/uploads/2012/07/Lamina-Geofert_MILHO.pdf> Acesso em: Jan. 2015. 